\title{
PROFESSIONALISM
}

\section{Technological determinism:}

A social process with some implications for Ambulance Paramedics

Article No. 990041

\section{Dennis McIntyre}

\begin{abstract}
Medical technology has been presented as a driving force behind a range of social changes, both positive and negative. These changes include escalating health care costs and inequalities in health care outcomes, the deskilling and hyperskilling of health care practitioners, and increased human longevity and quality of life. Medical technology is sometimes clouded by mystique in that each new drug, device, or machine tends to appear as a thing with a life of its own, as if the technology not only arrived independent of social, cultural, political and economic forces but was also the driving force for social change. By not considering the emergence and adoption of a medical technology as a social process, the resulting social change appears as a natural consequence of technological innovation.
\end{abstract}

This has been termed technological determinism.

This paper examines technological determinism as a social process and provides some explanation as to why ineffective, expensive, and harmful medical technologies have proliferated since the late 1970's. Four implications arising from technological determinism are identified, and they all have consequences for Ambulance Paramedics and their everyday practice as health care professionals.

Firstly, the intuition acquired as a skilled practitioner cannot be replaced by technology and an increase in invasive interventions has resulted in increased iatrogenesis. Secondly, there can be the blocking of a more effective and/or cheaper technology due to the resistance of powerful commercial and/or status groups. Thirdly, borrowing/sharing the technological symbols of an already dominant group may only serve to continue and/or construct a subordinate relationship. Fourthly, there can be a devaluing of Ambulance Paramedics when success is attributed to a technology rather than the skills of practitioners who use it.

Keywords: technological determinism; iatrogenesis; medical dominance; professional autonomy; evidence based medicine 


\section{Who would save your life?}

Every year I deliver a unit of study called Foundations of Health Sociology to approximately twelve hundred students in the health sciences at the University of Sydney. In the early part of my interaction with the first-year students I ask them the following question. If you were to lose consciousness, get run over, or suffer some trauma (today); who would most likely stabilise your condition and possibly save your life?

The response is never good news for the ambulance service! Most students maintain that a doctor will save their life. As if, somehow, there are doctors patrolling the streets (complete with 'crash trolley') just waiting to come to the rescue. Somehow they believe that they would wake up in hospital (preferably a five-star private hospital), and to their delight find that they have been given a brain transplant by one of Australia's leading medical specialists. Luckily the students' beliefs also extend to incorporate the existence of an available compatible brain, and adequate health insurance protection to cover the entire costs of all their medical procedures.

Perhaps this fantasy could be explained by the fortunate fact that these otherwise fit and healthy young people have probably never experienced a life threatening situation such as heart attack or being pulled from a car wreckage. Perhaps it is just a case of the ambulance service being taken for granted, like electricity, sanitation and clean drinking water. Hence, the general response of "Yep, we know that. But it is still a doctor who saves your life". The more dogmatic even declare that the ambulance service does little more than provide the stretcher bearer and driver.

An example of this type of public perception was highlighted by the media coverage of ${ }^{\mathrm{i}}$ Kerry Packer's near fatal heart attack. Aspects of the story are probably well known to most Australians; however, for those of you who are not familiar with the events of that day in 1998, here is a brief summary:

Kerry Packer was playing polo at Warwick Farm (outskirts of Sydney, New South Wales) when he suffered a sudden heart attack. Fortunately there was an ambulance unit in attendance at the time, which just happened to be one of only two units in the New South Wales Ambulance Service equipped with a defibrillator and paramedic staff competent in its use. On the way to the closest public hospital in the area (Liverpool), ambulance paramedics resuscitated Kerry Packer and successfully stabilized his condition upon reaching the accident/emergency section of the hospital. From there, Kerry Packer was airlifted to Saint Vincent's private hospital in the City of Sydney where the late Doctor Victor Chang (then pioneering cardiac surgeon) performed by-pass surgery.

What was not emphasized and reiterated in the media coverage following the incident, were the merits of the ambulance personnel who delivered a living, rather than deceased, Kerry Packer to hospital. The crucial roles of accident/emergency staff in the public hospital sector should also be acknowledged, because (in New South Wales) few emergency departments exist in private hospital sectors. Instead, according to the media reports of this episode, Doctor Chang and Saint Vincent's Private Hospital were the stars. What were the names of the paramedics who brought Kerry Packer back to life? Even the defibrillator became a star, and henceforth became known as the 'Packerwacker'.

One positive outcome of this incident was that a grateful and generous Kerry Packer funded the provision of defibrillators to the NSW Ambulance service. As a consequence emergency life support, especially in the case of cardiac arrest, can now be delivered at the scene of the

\footnotetext{
${ }^{\mathrm{i}}$ Kerry Packer is an Australian business and media tycoon.
} 
'accident' to a wider population. As for Kerry Packer, all seem to be aware of his enormous personal wealth and reports concerning his state of health. However, his gratitude to, and interaction with, the ambulance service and its paramedic staff has become an historical footnote.

Rather than a rationed item, defibrillators seem to have become a take-for-granted technology that the general public now expects to be produced as a matter of course - and not just by ambulance paramedics. ${ }^{1}$ However, the introduction of a technology is not always so straightforward and so beneficial to so many. Nor is acquisition and distribution of the best medical technology a guaranteed outcome.

A cornerstone of Foundations of Health Sociology is the proposition that 'health is politics'. Students are initially uncomfortable with this idea because it challenges several of the takenfor-granted ideas about states of health and the provision of health care in Australian society. One idea is that health care is simply defined as the curing of disease and the restoration of physical wellbeing. A second idea is that health care generally takes place in centres of technological excellence called hospitals, under the direction of technical experts called doctors. A third idea is that the major limitation to human advancement and wellbeing is insufficient knowledge and technology, and that once the science and the technology are available all will be well and pathologies such as HIV/AIDS will become footnotes in medical history. The fourth idea is that health care is far too important to be sullied by politics, and this generally refers to the policies of the various political parties in their quest to attract electoral support. ${ }^{\text {ii }}$

One of the tasks allocated to the health sociologist who is employed in the field of health and illness is the application of critical inquiry to the many ideas and practices that support the domination of a disease management rather than a disease prevention and health care system in Australia. Evan Willis has termed this historical process 'medical dominance' and maintains that medical dominance is an account of the most successful and enduring political seizure of power in Australia over the past 150 years. Willis maintains that the origins of this dominance are not located in scientific advancement and/or technological innovation, but in the granting of a monopoly of practice (by the State) to the institution of medicine. ${ }^{2}$ Nurses, physiotherapists, radiographers, and ambulance paramedics to name but a few, also have occupational histories and role models, which involves taking control of their own training/education curricula and the technologies that are central to their work as health care practitioners. Moreover, their everyday practice informs them that health care is an arena of struggle around the political economy of who gets what, how much, and when? Their everyday practice also informs them that the interests of governments (State and Federal), citizens as consumers of health care, health care practitioner groups, and the corporate health industry are rarely, if ever, mutually shared. ${ }^{3}$ One site of contestation is medical technology, and the purpose of this paper is to unpack the ideology of 'technological determinism' by treating it as a social process.

\footnotetext{
${ }^{\text {ii }}$ I am providing this information to establish two points. First, these students as a reference group provide an insight into the mainstream beliefs and practices of other young Australian men and women. Second, The Australian Sociological Association (TASA) has a health section and, for over a decade at the annual TASA conference, many of the observations that I have reported have also been reported by other health sociologists teaching in similar programs at all of Australia's thirty-eight public universities. This is evidenced by the avalanche of health sociology textbooks in the past decade.
} 


\section{Technology as science and progress}

Almost every day the media trumpets news about the arrival of a new drug, a new surgical innovation, a new machine or device to replace a body organ or function, a new diagnostic test, or the use of molecular biology and genetic engineering to modify plants and animas, including humans, at the molecular level. There is indeed what Evan Willis has termed a 'techno phoria' (a misplaced optimism that scientific discovery and technological innovation will find a cure for everything) surrounding many of these developments. Ray Moynihan, an award winning medical journalist and advocate of evidence based medicine, has rightly argued that too much medical technology can actually be harmful to your health. These views are understandable when it is considered that the major technologies of Western medicine encompass surgery, radiation and pharmaceuticals and that each exposure to an interventionist/curative technology also carries a risk of 'iatrogenesis', namely injury due to infection, allergic reaction and so forth. ${ }^{4}$ Fran Collyer, who has written extensively on the sociology of medical technology, maintains that:

Technology is a significant component of the health care budget [and it is access to new technologies which blows out budgets]. Yet it is difficult to estimate exactly what proportion of a budget is taken up by technology. Is technology just the machines and equipment used by a hospital or clinic [or ambulance service]? Can a surgical technique or a new method of blood analysis be described as a technology? Are new areas of knowledge about health care a form of technology? If knowledge and information can be considered as technologies, then should the purposes and intentions behind their creation be included as part of the technologies? ${ }^{5}$

Collyer raises these fundamental questions to challenge the view that technology in all its forms is object-centred. From this perspective technology is understood as just machines and devices (especially of the 'gee-wiz' variety) and/or 'something that is wholly external to social relationships and consequently outside of human control'. ${ }^{6}$ Technology (medical or otherwise) is not a thing that appears ready made (a gift from the gods), nor is it a natural object like air, fire and water. New technologies emerge as an outcome of social interaction (battles, negotiations, persuasions, etc), and there is no guarantee that the best invention survives. As explained below, the domestic refrigerator is but one example of this process.

\section{Technology as a social interaction}

Have you seen or used a gas-powered refrigerator? Until the 1920s domestic refrigerators were a simple technology; little more than an insulated metal cabinet that contained an ammonia filled coil that was heated by a thermostatically controlled gas flame. The refrigeration was produced by the expansion and contraction of the ammonia gas. According to engineers, the gas refrigerator having no moving parts (an electric motor and compressor) was technically superior, cheaper, and quieter than its replacement - the electric powered refrigerator. In what has become a classic case study, Donald MacKenzie and Judy Wajcman explain how the refrigerator got its hum.

In the 1920's the electricity generating companies such as General Electric decided to expand into the manufacture of stoves and refrigerators (what became known as white goods) to increase the sale of electric power and, as a consequence, an electricity generating plant. As this happened in a pre-television age, Hollywood was enlisted to produce advertising film that 
featured movie stars in a glamorous 'all electric' kitchen. Showrooms were built in major centers of population and celebrities would meet the public at the launch of the electric kitchen.

The coal-gas companies, moribund by being a near monopoly provider of town energy for almost a century, did not respond to this latest challenge and by the late 1940s electric kitchens had become the rule rather than the exception. Now, except for a handful of 'campervan' enthusiasts, the general public takes it for granted that the electric refrigerator is the only available technology, or that the gas-powered refrigerator (now a novelty) was invented last year.

Since the early part of the twentieth century advertising firms have known that the commodity is both the cause of and the solution to the consumer's discontent. According to John Berger this discontentment has to be manufactured and the potential consumer needs to be sold the idea that they need not be deprived of what they need to be able to enjoy the good life. ${ }^{8}$ In short, the consumer was not buying a refrigerator or a stove - but glamour. With the electric refrigerator, the latest was not the greatest! Researchers who I have cited (Moynihan, Collyer, and Willis) also use Berger's thesis to partially explain the manufacturing of consumer demand for some medical technologies and the corresponding impact that this has on already overstretched health care budgets.

\section{Technology as symbolism}

Symbols are cultural artifacts that convey status and legitimation. In 1990 I conducted a study into occupational stressors for and with the Newcastle bus operators and their union. The bus operators had earlier decreed that they were not going to 'piss in any more bottles, give any more blood samples, or wear any more heart monitors'. They were sick of being the objects of medical research and wanted some action. The study found that the major iii occupational stressor was timetables and rosters and those other occupational stressors such as increased passenger complaints and cutting corners (speeding etc) were largely caused by unrealistic timetables. ${ }^{9}$

The media were interested in this study and I agreed to give several television interviews at my workplace (The University of Newcastle). Near my office there was a simulated nursing ward replete with the latest technology, and on one occasion I agreed to this venue as the interview site. Having an oxygen bottle and a life support monitor as a backdrop was one thing, but when I refused the request to wear a white coat and stethoscope the initial enthusiasm of the production team seemed to wane. Perhaps this section of the media considered that it was the basic symbols of medical science (rather than the quality of the evidence) that legitimized knowledge claims; even when the research findings, which concerned the relationship between timetables, fatigue, pace of work, and occupational illness, had nothing to say about the clinical nature of pathologies (such as cardiac arrest and hypertension) which is the substantive matter of medical science.

It is not just the social researcher who has problems with the symbols of technology. Sufferers of asthma use a range of medications to assist their breathing. Generally, these medications are inhaled through a nebuliser (an electrically operated air pump which delivers vaporized medication through a connected breathing mask) or a hand-held bronchio-dilator colloquially called a 'puffer'. According to chronic asthma sufferers, the advent of the 'puffer' accorded

\footnotetext{
${ }^{\text {iii }}$ As part of the research designs all bus routes were traversed at 3.00am by car. The road traffic rules were strictly followed and there were no stops for picking up and putting down passengers. Sixty percent of the routes could not be completed in the scheduled time. That is why the bus operators were 'stressed out'.
} 
them a mobility and sense of security that they had never enjoyed before. This was further enhanced by the arrival of the 'spacer' (a plastic tube with a non-return valve in one end) that was used in conjunction with the puffer when a quick-acting dose of medication (such as Ventolin $($ ) was required. Moreover, when a spacer is used, a learned coordination between inhalation and activation is not required. The spacer is indeed a technology for 'dummies'. The nebuliser, on the other hand, is relatively expensive (compared to a puffer and spacer), is heavy and bulky, and requires regular recharging and maintenance. Nonetheless, as a 'passive' technology its application is vital when airways have narrowed, particularly in young and elderly sufferers who cannot use a puffer.

Australian research led by Dr. Madlen Gazarian suggests that that in most cases a spacer delivers the bronchio-dilator medication to the lungs more efficiently than a nebuliser. ${ }^{10}$ However, if the sufferer presented at accident/emergency they would most likely be placed on a nebuliser in the first instance - irrespective of their physiological and/or mental condition. Dr. Norman Swan (presenter of ABC radio's Health Report) asked Madlen Gazarian to explain this aspect of the research. Here is an extract from that interview: ${ }^{11}$

Madlen Gazarian: Well it seems like a paradox, doesn't it, that a way of delivering medicine which is a nebuliser has been a long-established practice for treating bad asthma attacks, or acute asthma attacks for which you need to go to hospital. It's a machine, there's lot of noise, there's lots of medicine floating all around the place.

Norman Swan: It must be good for you.

Madlen Gazarian: That that's got to be better, and the simple concept that that's actually perhaps not such a good way of delivering medicine. You can understand why people would find that difficult to believe. The other thing to emphasize is that what I've just explained to you earlier about why spacers should work well is based on what we would call first principles, or scientific principles of what should work, and that doesn't always necessarily translate into what does work in actual fact. And the beauty about this spacer device is that it has in fact been studies in clinical trials which have demonstrated that the principles are borne out in actual use, that there are benefits.

Norman Swan: And is there a belief that if you use spacer devices outside the hospital more for regular treatment that you could actually prevent the child ever going to the emergency room in the first place?

Madlen Gazarian: I guess that's a possibility that the trials upon which we based our practice, didn't necessarily report on that aspect. It could be that people are coming to hospital for an asthma attack because they don't have a nebuliser at home; a nebuliser is an expensive device, whereas a cheaper spacer device if it were available at home and could deliver the medication effectively, yes, it may prevent hospital presentation.

Norman Swan: Dr. Gazarian and her colleagues at the Sydney Children's Hospital decided to see whether they could get their colleagues in the Emergency Department to adopt spacer devices and stop using nebulisers when they weren't needed. As an example of how hard it can be to introduce what's called evidence-based practice, even in a centre which would regard itself as first class, the process took months to implement, using various educational techniques to change the behaviour of the doctors, nurses and pharmacists. But it paid off.

Later researchers (Adams, Cates, Bestall) rightly maintain that 'cost, compliance and patient preference are important determinants of clinical effectiveness that have not been assessed' in the spacer versus nebuliser debate. ${ }^{12}$ However, in this section, it is the symbolism of 
technology and not the clinical usefulness of either application that is being emphasized. The nurses and doctors had held the belief that a machine must be superior technology to what at first glance resembled a deformed plastic bottle. The usefulness of the technology notwithstanding, it is also the symbolism of the technology and what it represents that has an impact on both the general public (the layperson) and the expert practitioner. In spite of evidence-based findings concerning clinical efficacy (or its lack), technology does hold some mystique and a capacity to provide a social space between the lay-person and the expert, and there is also the power of tradition.

\section{Knowledge/power and technology}

Post-structuralist theorists (such as Michel Foucault) maintain that power and knowledge are wedded together as power/knowledge and imply each other. ${ }^{13}$ The expert has the power/knowledge to define the other as normal or abnormal. That is, 'discourses' have truth effects that give rise to discursive practices (treatment regimes). Some of these practices are actually harmful to health and are not supported by 'good' science. A post-structuralist perspective essentially maintains that knowledge and experts are socially constructed and that experts also have 'power over' individuals and the 'power to' influence public policy.

Foucault's method was to use the past in order to problematise the present by challenging the way that knowledge, as a claim to 'truth', is taken-for-granted by human beings in constructing their understandings of reality; human beings do not have access to reality outside of their own understandings of it. Foucault maintains that these understandings of reality are organised into discourses that involve the classification of a body of knowledge, and the identification of whom, and in what circumstances and/or locations, can make 'knowledge claims'. Foucault's project was to identify and trace changes in these discourses, which privilege or marginalise particular kinds of knowledge and by implication - technologies.

The acceptance of a new body of knowledge (a scientific paradigm) does not always occur because the new paradigm is more correct in the solutions that it advocates for the resolution of a particular problem. The holders of the old paradigm generally resist because their ideal and material interests are at risk (status as an expert and income are prime candidates). The knowledge about ulcer disease of the stomach (discourse) and treatment (discursive practice) has undergone a radical change since the early 1980s, but this was a 'battle royal' rather than the celebration of a great discovery. With the arrival of the Helicobacter pylori thesis on stomach ulcers; millions of dollars in terms of pharmaceutical sales were at risk. ${ }^{14}$

\section{Technology as a commodity}

Until the 1970s ulcer disease generally thought to be a nervous ailment, was treated with psychological counselling and diet (avoidance of fatty foods, cigarettes, and alcohol). The emergence of 'anti-acid theory' (in lay terms, acids that attacked the gut were neutralised) resulted in the development and marketing of H2-antagonist drugs sold under the names of Tagamet $₫$ (cimetidine) and Zantac ${ }^{\circledR}$ (ranitidine). In Australia alone, pharmaceutical companies earned millions of dollars a year from these drugs. Two researchers Robert Warren (a gastroenterologist) and Barry Marshall (a microbiologist) investigated the presence of bacteria in the biopsies of ulcerated stomach tissue and identified the presence of a micro-organism (later classified as Helicobacter pylori). They were then able to theorise that ulcer disease is caused by an infection of the stomach lining, not the 'over-production' of gastric acids. This finding challenged the orthodox view that the stomach was a sterile environment, exposed weaknesses in surgical and treatment protocols, and helped to explain why ulcers generally returned after the taking of anti-acid medications. According to Collyer who has provided a 
riveting account of the responses by the medical establishment and the pharmaceutical companies wrote:

"The case of ulcer disease illustrates clearly that technologies enter or remain in the market place by virtue of social factors, not 'objective market forces' or even consumer/patient demand. In this case the profit motive of pharmaceutical companies, and the scepticism and entrenched beliefs of practitioners, have both been instrumental in blocking technological change." 15

One positive outcome of this scientific/technological revolution is that Zantac can now be purchased over the counter without a prescription, and for a modest price. The explanation as to why Zantac was initially rationed, is that a commercial interest was shaping the situation. Exchange value was more important than use value (relief of suffering), and the government controlled ${ }^{\text {iv }}$ PBS (Pharmaceutical Benefits Scheme) which exists in Australia could not afford to issue the pharmaceutical industry with an open cheque.

\section{Latest is the Greatest}

In this paper, considerable reference has been made to the role of undergraduate students in the health sciences, and the ideas that they bring to the academy (not just at the University of Sydney). The ideas that the 'latest is the greatest' and that more technology translates into more knowledge are generally taken for granted. Yet, some technologies have a 'dumbing down' capacity. For instance, the instructional Microsoft ${ }^{\circledR}$ technology called PowerPoint ${ }^{\circledR}$ is also known as digital hemlock. ${ }^{16}$ The role of the social sciences, especially when interacting with the next generation of health care practitioners is to call for evidence about knowledge claims and the efficacy of practice. Part of this challenge comes from what has been termed 'evidence based medicine', but this approach generally examines knowledge claims and clinical outcomes rather than the processes that produced those outcomes. Nonetheless, the findings of evidence based medicine have demonstrated that some hitherto 'scientific facts' about some medical practices were based on some fairly fragile scientific foundations.

How then did some of these knowledges and practices become facts (written in textbooks and examinations) and why did they remain as unquestioned certainties for so long? Part of the answer resides in thinking about the production of technology as a social process. All technologies are invented, designed, developed, marketed, manufactured and finally introduced into medical and paramedical practice by a socially mediated process that is shaped by the interaction between social institutions, the history and culture of the society and its dominant belief systems, and the political and economic structures that dominate nationally and globally. This process also involves innovation, interactionism, and commodification (though not necessarily in that order). A technology (be it knowledge, defibrillators, refrigerators, nebulisers, spacers, or Zantac) is value neutral because it does not have a life of its own. It is social relationships such as ownership, control, and the application of a technology - not the technology itself - that shapes social change and health outcomes. Some of these outcomes are indeed positive, and others give rise to iatrogenesis.

\footnotetext{
iv The PBS is administered by the Australian Government and subsidizes the provision of approved pharmaceuticals (and other technologies) to Australian citizens. The PBS regulates the cost of pharmaceuticals that qualify for a subsidy and effectively controls supply and demand. Although the PBS is the envy of most OECD countries, the World Trade Organization considers the PBS to be against the interests of free markets.
} 


\section{Conclusion}

Four implications arising from technological determinism have been suggested in this paper, and they all have consequences for Ambulance Paramedics and their everyday practice as health care professionals.

Firstly, in the accident/emergency setting it is the first skilled person on the scene (with or without technology) who will save a life. The skill and intuition acquired as a practitioner takes time and experience that cannot be replaced with more technology.

Secondly, there can be barriers to objective evaluation of more effective and/or cheaper technology, due to the resistance of powerful commercial and/or status groups. As a consequence, funding that may have been intended for other needs (such as more staff), is diverted to the unnecessary acquisition of newer and sometimes less efficient technology, or retention of old technology which should be replaced.

Thirdly, borrowing/sharing the technological symbols of an already dominant group may only serve to continue and/or construct a subordinate relationship. Generally, it is when the occupational group can claim a monopoly of expertise in the use of the technology that the symbolism of the technology reinforces the knowledge claims of the user.

Finally, there can be a devaluation of occupational community - such as Ambulance Paramedics - when success is attributed to a technology alone, rather than the skills of practitioners who use it.

1. Sheather, R. 'To shock or not to shock', conference paper abstract, ACAP National Conference Expanding Horizons-A Fresh Perspective 19-20th September 2003. Journal of Emergency Primary Health Care. 2003;1(3-4)

2. Willis, E. (1989) Medical Dominance: The Division of Labour in Australian Health Care (Revised Edition), Sydney: Allen \& Unwin.

3. Mahony, K. 'The Politics of Professionalisation: Some Implications for the Occupation of Ambulance Paramedic in Australia', unpublished paper, ACAP National Conference Expanding Horizons-A Fresh Perspective 19-20th September 2003. Journal of Emergency Primary Health Care. 2003;1(3-4)

4. Moynihan, R. (1998) Too much Medicine: The Business of Health-And Its Risks For You, Sydney: ABC Books.

5. Collyer, F. (1999) 'The Social Production of Medical Technology, in Gribich, C. (Ed) Health in Australia: Sociological Concepts and Issues (Second Edition), Sydney: Longman, p. 219.

6. Collyer, F. 'The Social Production of Medical Technology. In: Gribich, C. (Ed) Health in Australia: Sociological Concepts and Issues (Second Edition), Sydney: Longman; 1999. p. 217-237.

7. MacKenzie, D. and Wajcman, J. (Eds.) The Social Shaping of Technology: How the Refrigerator Got its Hum. Milton Keynes: Open University Press; 1985.

8. Berger, J. (1972) Ways of Seeing. London: British Broadcasting Corporation.

9. McIntyre, D. 'Occupational Stressors: An Insidious Form of Assault', in Waddell, C. and Petersen, A. (Eds) Just Health: Inequality in Illness, Care and Prevention. Melbourne: Churchill Livingstone; 1994.

10. Gazarian M. et al. Evaluating the effectiveness of evidence-based guidelines for the use of spacer devices in children with acute asthma. Medical Journal of Australia. 200116 April;174:394-397. 
11. Swan, N. Effectiveness of Spacer Devices in Children with acute Asthma. ABC Radio National broadcast Monday 23 April 2001 [transcript cited 2004 Mar 3]. Available from:http://www.abc.net.au/rn/talks/8.30/helthrpt/stories/s281876.htm

12. Adams N, Cates CJ, Bestall J. 'Holding chambers versus nebulisers for inhaled steroids in chronic asthma' (Cochrane Review). In: The Cochrane Library, Issue 1, 2004. Chichester, UK: John Wiley \& Sons, Ltd.

13. Philp, M. 'Michel Foucault'. In: Skinner, Q. (Ed) The Return of Grand Theory in the Human Sciences. Melbourne: Cambridge University Press1985. p. 65-81.

14. Collyer, F. 'Understanding Ulcers: Medical Knowledge, Social Constructionism, and Helicobacter pylori', Annual Review of Health Social Sciences 1996;6:1-39.

15. Collyer, F. 'Understanding Ulcers: Medical Knowledge, Social Constructionism, and Helicobacter pylori', Annual Review of Health Social Sciences. 1996;6:23.

16. Brabazon, T. Digital Hemlock: Internet Education and the Poisoning of Teaching, Sydney: UNSW Press; 2002. 